\title{
Model Manajemen Pembelajaran Online Pada Pendidikan dan Pelatihan Guru Pendamping Muda PAUD
}

\author{
Natalia Dewi Mumpuni \\ Magister Manajemen Pendidikan Universitas Kristen Satya Wacana \\ uniqmumpuni@gmail.com \\ Bambang Ismanto \\ Magister Manajemen Pendidikan Universitas Kristen Satya Wacana \\ bambang.ismanto@uksw.edu
}

\begin{abstract}
The purpose of this study is to (1) Explain the Implementation of Education and Training of young assistant teachers in Central Java; (2) Explain the weaknesses of the education and training of young assistant teachers in Central Java; (3) Describe the Educational Management Model and training of PAUD young assistant teachers through online media. Early Childhood Teacher Education and Training is a series of tiered PAUD teacher education and training owned by the Ministry of Education and Culture that can be organized by institutions that meet the requirements or have been designated as training providers. Online media used in this research are Information Systems and Video Conference Webex cisco meetings. The final product of this research is a model and supporting material in the form of a guide, which consists of a guide for participants, a guide for field officers and a guide for facilitators. This research and development uses a mixed method, using the seven steps of development from Borg and Gall, which is integrated with the ADDIE model. Data collection methods use instruments in the form of questionnaires, interview guidelines, and tests. The research subjects were organizers, field officers, facilitators, and training participants. Data analysis techniques using quantitative and qualitative descriptive. The results of the main trial phase showed that the education and training of PAUD young teacher assistants through online media was effective in increasing competency, this was seen from the increase in pre-test to post-test average points which rose 32 points and the graduation rate of participants was $98.2 \%$.
\end{abstract}

Keywords: Management, Education and Training of Young Teacher Assistance, PAUD, Online Media

\section{Article Info}

Received date: 10 Desember 2019

Revised date: 20 Desember 2019

Accepted date: 20 Desember 2019

\section{PENDAHULUAN}

Pendidikan Anak Usia Dini (PAUD) masih menjadi fokus pembangunan pendidikan di Indonesia tahun 2019 (Renstra Kemendikbud, 2015: 39). Selama periode 2011-2016, pemerintah bekerja sama dengan masyarakat berhasil meningkatkan angka 206 partisipasi PAUD menjadi $34,62 \%$ pada tahun 2016 atau naik $10,12 \%$ dari capaian pada tahun 2011 yaitu sebesar 24,50\% (BPS, 2018). Hal tersebut menunjukkan bahwa PAUD semakin berkembang dan dibutuhkan masyarakat, sehingga kebutuhan akan adanya guru PAUD 
yang berkualitas semakin besar ketika jumlah satuan PAUD juga semakin banyak.

Keberhasilan PAUD tidak terlepas dari peran guru, mengingat kiprahnya dalam pengasuhan, perawatan, pendidikan dan perlindungan anak dalam upayanya mengoptimalkan kecerdasan dan perkembangan anak usia dini.

Pemerintah telah mengeluarkan standar Pendidik PAUD yang terdapat pada Permendikbud Nomor 137 Tahun 2014. Dalam peraturan menteri tersebut dinyatakan bahwa terdapat tiga level atau tingkatan pendidik PAUD yaitu,guru, guru pendamping, dan guru pendamping muda dengan masing-masing kualifikasi kompetensi yang harus dipenuhi. Kualifikasi dan kompetensi inilah yang akan menentukan tingkatan wewenang dan tanggung jawab dalam pelaksanaan tugasnya sebagai pendidik PAUD.

Namun secara faktual, berdasarkan hasil Pemetaan MutuPAUD (Ditjen PAUD dan Dikmas, 2018), kompetensi dan kualifikasi pendidik PAUD memiliki variasi yang sangat tinggi. Dari sisi latar belakang pendidikan misalnya, masih ditemukan pendidik yang berlatar belakang pendidikan dasar (SD atau SMP), dan sedikit yang berlatar pendidikan pendidikan sarjana. Diantara yang berpendidikan sarjana tersebut banyak yang bidang keilmuannya tidak berkaitan dengan pendidikan anak usia dini. Selain itu banyak pendidik PAUD yang mengajar tidak sesuai dengan level, wewenang dan tanggung jawabnya. Lembaga PAUD masih ada yang tidak memiliki pendidik berkualifikasi sarjana, sehingga menurut standar pendidik, lembaga tersebut dianggap tidak memiliki pendidik dengan level guru.

Salah satu upaya untuk mengatasi kesenjangan kompetensi sekaligus memenuhi kebutuhan guru yang sesuai standar nasional PAUD tersebut, maka diselenggarakan Pendidikan dan Pelatihan (Diklat) bagi guru PAUD. Diklat merupakan sebuah rancangan kegiatan yang bertujuan untuk meningkatkan pengetahuan, kecakapan dan keterampilan guru terhadap keseluruhan lingkup kerjanya (Utami, 2018:3).

Diklat berjenjang bagi guru PAUD menjadi pilihan Pemerintah sebagai upaya agar guru PAUD memiliki tugas dan wewenang sesuai dengan kompetensi dan kualifikasiseharusnya. Diklat berjenjang PAUD terdiri dari 3 jenis, yaitu (a) Diklat berjenjang tingkat dasar; (b) berjenjang tingkat lanjut; dan (c) Diklat berjenjang tingkat mahir. Sejak tahun 2018 Diklat Berjenjang diselaraskan menjadi Diklat Guru Pendamping Muda (Diklat Berjenjang Tingkat Dasar), Diklat guru pendamping (Diklat berjenjang tingkat lanjut) dan Diklat guru (Diklat berjenjang mahir) mengikuti standar Kerangka Kualifikasi Nasional Indonesia/KKNI (e-paper Media Indonesia, 2018).

Pendidikan dan pelatihan Guru Pendamping Muda adalah Diklat berjenjang tingkat dasar bagi pendidik atau guru PAUD agar memiliki kesiapan sebagai pendidik PAUD di level guru pendamping muda.Beban belajar Diklat tersebut sebanyak 48 jam pelajaran@ 45 menit dan 210 jam pelajaran tugas mandiri.

Diklat dengan memanfaatkan teknologi informasi dan komunikasi menjadi sebuah keniscayaan yang akan mendominasi penyelenggaraan diklat di masa yang akan datang. Hal ini disebabkan karena jumlah anggaran yang ada tidak sebanding dengan jumlah sasaran yang ada. Butuh waktu yang lama dan anggaran yang besar untuk menuntaskan sasaran guru yang ada jika hanya mengandalkan diklat konvensional atau tatap muka langsung. Begitu pula dengan diklat berjenjang bagi guru PAUD yang pada akhirnya akan lebih banyak diselenggarakan melalui media online, untuk mempercepat ketuntasan guru PAUD mengikuti diklat berjenjang. 
Agar fungsi manajemen seperti perencanaan, pengorganisasian, pelaksanaan, dan pengendalian diklatnya dapat berjalan dengan baik dan menghasilkan keluaran yang baik, maka dibutuhkan manajemen diklat yang handal. Manajemen di sini dalam pengertian usaha untuk mencapai tujuan yang dilakukan oleh kumpulan orang atau seseorang yang melakukan aktivitas manajemen berupa perencanaan, pengorganisasian, pelaksanaan dan pengendalian dalam suatu organisasi dengan memanfaatkan sumber daya man, money, machine, material, method dan Market(Terry, 1956: 28).

$$
\text { Rachman }
$$

yang

mengungkapkan tentang urgensi pengaturan dan pengelolaan dalam penyiapan desain kegiatan online, alat pembelajaran, desain jaringan, strategi penyampaian materi serta instrumen evaluasi agar diklat online dapat berjalan dengan baik.Rachman (2018:1) mengungkapkan bahwa Diklat online sebelumnya menggunakan metode pembelajaran tatap muka online, pembelajaran tutorial online, dan pembelajaran mandiri. Metode online individu seperti itu memiliki kelemahan yaitu tidak adanya pengawasan secara langsung ketika tes, dan tidak bisa mengadakan peer teaching.

Berdasarkan beberapa hal tersebut diatas, maka penelitian ini mengembangkan model manajemen diklat guru pendamping muda (berjenjang tingkat dasar) melalui media online, yang dapat menyelenggarakan diklat online berkulitas, menggunakan sistem informasi (asynchronous) dan video conference (synchronous) yang di dampingi oleh petugas lapangan. Hal tersebut sejalan dengan pendapat Budiyanto dan Pujiyono (2014:2) mengatakan bahwa pembelajaran berbasis internet atau online akan efektif apabila memadukan layanan online jenis asynchronous (online tidak langsung) dan synchronous (online secara langsung).
Pengembangan Model Diklat guru pendamping muda PAUD melalui media online ini mendeskripsikan Penyelenggarakan Pendidikan dan Pelatihan guru pendamping muda di Jawa Tengah, Mendeskripsikan kelemahan dari pendidikan dan pelatihan guru pendamping muda yang selama ini dilaksanakan di Jawa Tengah, serta Mendeskripsikan Model Manajemen Pendidikan dan pelatihan guru pendamping muda PAUD melalui media online.

\section{METODE PENELITIAN}

Penelitian ini merupakan Penelitian dan Pengembangan (Research and Development). Peneliti mengacu pada prosedur penelitian dan pengembangan Borg dan Gall sampai langkah ke-tujuh yang di integrasikan dengan model pengembangan ADDIE (Borg\&Gall; 1983:775, Pribadi, 2014: 23). Integrasi keduanya seperti yang ada di gambar berikut:

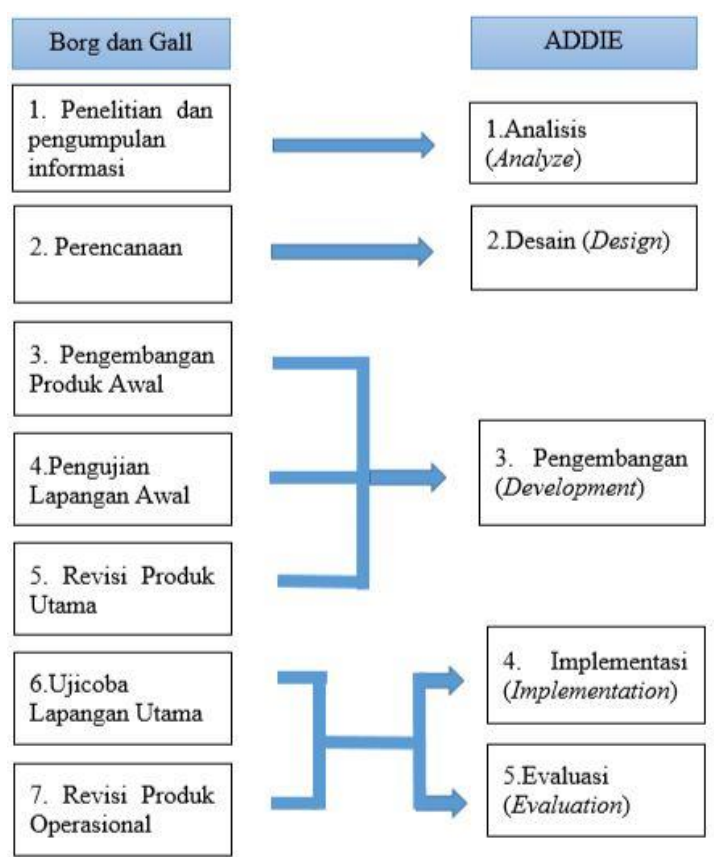

Gambar 1. Prosedur Borg dan Gall terintegrasi Model ADDIE

Pendekatan penelitian yang digunakan adalah pendekatan kuantitatif dan kualitatif. Pendekatan kuantitatif menggunakan teknik pengumpulan data berupa angket, dan pengumpulan data kualitatif dengan teknik 
wawancara dan studi dokumentasi. Sehingga teknik analisis datanya juga menggunakan analisis data kuantitatif dan kualitatif.

Subjek penelitian pada tahap penelitian dan pengumpulan informasi serta tahap pengujian lapangan awal adalah penyelenggara, fasilitator, peserta Diklat, serta petugas lapangan.

Pada tahap ujicoba utama, subjek penelitian ini adalah peserta Diklat guru pendamping muda melalui media online dan teknik pengambilan sampelnya dengan total sampling sebanyak 111 orang, karena semua populasi dijadikan sampel penelitian.

\section{HASIL PENELITIAN DAN PEMBAHASAN}

\section{Hasil Penelitian}

1. Penelitian dan pengumpulan informasi Hasilnya menunjukkan bahwa diklat guru pendamping muda PAUD yang dilaksanakan di Jawa Tengah sudah mengacu pada pedoman (Ditjen PGTK PAUD Dikmas, 2018) yang telah dikeluarkan oleh kementerian pendidikan dan kebudayaan, namun terdapat beberapa permasalahan bagi penyelenggara terkait jumlah dana yang dianggarkan pemerintah, keterbatasan jumlah sumber daya manusia untuk menangani diklat, kurangnya koordinasi antar panitia dalam rangkaian proses diklat, serta dalam hal waktu dan tempat.

2. Perencanaan

Peneliti menyusun perencanaan untuk mengatasi kelemahan-kelemahan penyelenggaraan diklat sebelumnya sebagai solusi dalam bentuk naskah model manajemen diklat guru pendamping muda melalui media online, agar menjadi acuan proses Diklat dari sejak perencanaan, pengorganisasian, pelaksanaan dan pengendalian.

Pengembangan Diklat memanfaatkan media online secara komprehensif antara online secara langsung (Synchronous) dan online secara tidak langsung (Asynchronous), supaya peserta yang tidak mendapatkan kesempatan mengikuti Diklat atas undangan Dinas Pendidikan, tetap bisa mengikuti Diklat tanpa membayar, di lokasi terdekat dengan rumahnya secara bersama-sama dengan peserta lain, serta tidak menganggu jam pembelajaran anak didiknya.

\section{Hasil Pengembangan}

1. Pengembangan produk awal

Peneliti menyusun model dan panduanpanduan, yang diuji validasi oleh ahli Diklat, ahli PAUD dan Ahli IT. Hasil validasinya menunjukkan bahwa produk Model berserta panduan layak digunakan. Secara lebih rinci dapat dilihat pada tabel berikut:

Tabel 1 Rata-rata uji Validasi Produk

\begin{tabular}{lll}
\hline No & \multicolumn{1}{c}{ Produk } & \multicolumn{1}{c}{ Rata-rata } \\
\hline 1 & Model & 3,52 \\
\hline 2 & $\begin{array}{l}\text { Panduan bagi petugas } \\
\text { lapangan }\end{array}$ & 3,56 \\
\hline 3 & Panduan bagi peserta & 3,61 \\
\hline 4 & Panduan bagi fasilitator & 3,58 \\
\hline
\end{tabular}

Sumber Data: Hasil Validasi

Hasil dalam tabel tersebut menunjukkan bahwa produk sangat sesuai digunakan untuk diklat.

2. Pengujian lapangan awal

Pengujian lapangan awal merupakan tahap dimana pihak-pihak yang terlibat diundang untuk mencermati isi model dan panduan yang telah direvisi, serta mencoba media yang ada, agar mengetahui kelayakan penggunaannya. Hasilnya secara rinci dapat dilihat berikut ini:

Tabel 2 Hasil Pengujian lapangan

\begin{tabular}{lll}
\hline No & Pihak yang terlibat Diklat & $\begin{array}{l}\text { Rata- } \\
\text { rata }\end{array}$ \\
\hline 1 & Penyelenggara & 3,83 \\
\hline 2 & Petugas Lapangan & 3,59 \\
\hline 3 & Peserta & 3,52 \\
\hline 4 & Fasilitator & 3,67 \\
\hline
\end{tabular}

Sumber data: Hasil Pengujian Lapangan awal 
Hasil tersebut menunjukkan bahwa model, panduan dan media sangat baik untuk digunakan dalam diklat.

3. Revisi Produk Utama

Produk model dan panduan direvisi sesuai masukan dari penyelenggara, petugas lapangan, peserta dan fasilitator. Media dan mekanisme penggunaannya pun disesuaikan dengan masukan yang ada.

4. Ujicoba Lapangan Utama

Pada tahap ujicoba utama, terdapat 111 orang peserta, di 7 lokasi grup online yang di koordinir oleh 7 orang petugas lapangan. Lokasi grup online ada di Kabupaten Semarang, Kota Salatiga, Kota Surakarta, Kabupaten Boyolali, kabupaten Magelang, Kabupaten Banjarnegara dan Kabupaten Klaten.

Alur diklat guru pendamping muda melalui online dapat di lihatpada tabel berikut ini:

Tabel 3 Alur Diklat

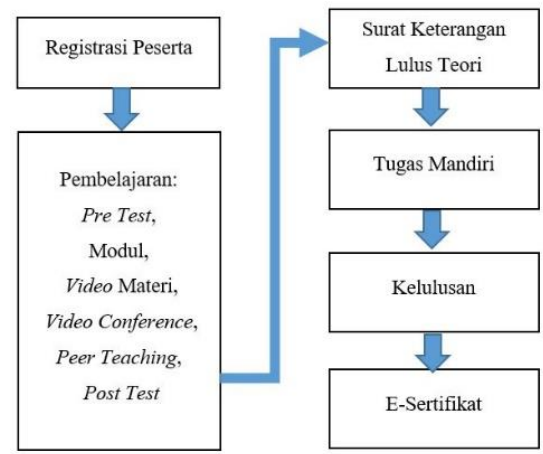

Sedangkan model Manajemen diklatnya seperti gambar berikut:

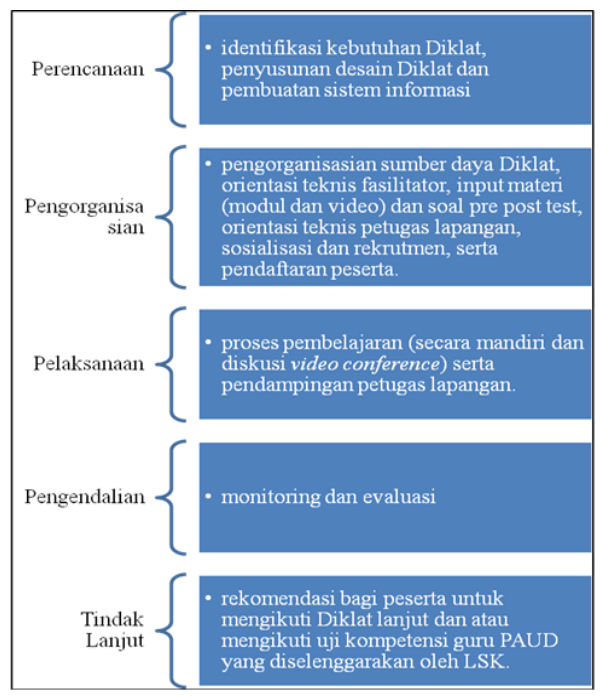

Gambar 2 Model Manajemen Diklat
Hasilnya Rata-rata hasil pre test peserta adalah 58, sedangkan rata-rata hasil post test peserta adalah 90. Selain data tentang pre test dan post test juga ada data tentang nilai tugas mandiri sebagai komponen pelengkap, rata-rata nilai tugas mandiri adalah 88 . Sehingga dari data post test dan tugas mandiri tersebut ratarata nilai akhir peserta adalah 89 , ini di atas standar minimal kelulusan yang hanya 75 . Akumulasi data menunjukkan bahwa dari 111 orang peserta Diklat, ada 109 yang lulus, artinya 98,2\% tingkat kelulusannya. Kesimpulannya diklat Guru Pendamping Muda melalui media online efektif meningkatkan kompetensi peserta dan menuntaskan peserta untuk lulus Diklat.

Lebih lanjut untuk melihat efisiensi, dapat dilihat pada tabel berikut:

Tabel 4 Perbandingan Dana

\begin{tabular}{|c|c|c|c|c|c|}
\hline \multicolumn{3}{|c|}{$\begin{array}{l}\text { Dana Diklat konvensional } \\
\text { (peserta } 40 \text { orang) }\end{array}$} & \multicolumn{3}{|c|}{$\begin{array}{c}\text { Dana Diklat melalui media } \\
\text { online (jumlah peserta tidak } \\
\text { terbatas) }\end{array}$} \\
\hline No & Rincian & Dana (Rp) & No & Rincian & Dana (Rp) \\
\hline 1 & $\begin{array}{l}\text { Honor } \\
\text { Fasilitator }\end{array}$ & 24.000 .000 & 1 & $\begin{array}{l}\text { Honor } \\
\text { Fasilitator }\end{array}$ & 24.000 .000 \\
\hline 2 & $\begin{array}{l}\text { Transpor } \\
\text { Peserta (40 } \\
\text { orang) }\end{array}$ & 10.000 .000 & 2 & $\begin{array}{l}\text { Belanja } \\
\text { Bahan } \\
\text { (ATK) }\end{array}$ & 500.000 \\
\hline 3 & $\begin{array}{l}\text { Akomodasi } \\
\text { Konsumsi } \\
\text { ( } 7 \text { hari) }\end{array}$ & 47.250 .000 & 3 & $\begin{array}{l}\text { Honor } \\
\text { Panitia } \\
\text { Orang) }\end{array}$ & 1.600 .000 \\
\hline 4 & $\begin{array}{l}\text { Belanja } \\
\text { Bahan } \\
\text { (ATK) }\end{array}$ & 8.500 .000 & 4 & $\begin{array}{l}\text { Pengadaan } \\
\text { Sistem } \\
\text { (untuk } \\
\text { berkali-kali } \\
\text { penggunaan) }\end{array}$ & 35.000 .000 \\
\hline 5 & $\begin{array}{l}\text { Honor } \\
\text { panitia } \quad(4 \\
\text { orang) }\end{array}$ & 1.600 .000 & 5 & Biaya Ortek & 20.000 .000 \\
\hline 6 & $\begin{array}{l}\text { Uang } \\
\text { Harian } \\
\text { Peserta }(40 \\
\text { orang, } \quad 7 \\
\text { hari) }\end{array}$ & 42.000 .000 & 6 & $\begin{array}{l}\text { Peralatan } \\
\text { Video } \\
\text { conference } \\
\text { di Host } \\
\text { (untuk } \\
\text { berkali-kali } \\
\text { penggunaan) }\end{array}$ & 17.000 .000 \\
\hline & TOTAL & 133.350 .000 & & & 98.100 .000 \\
\hline
\end{tabular}

Sumber data: Laporan Diklat PP PAUD dan Dikmas Jawa Tengah

Tabel tersebut menunjukkan bahwa Diklat guru pendamping muda melalui media online lebih efisien daripada Diklat guru pendamping muda konvensional, karena dengan jumlah dana yang relatif lebih sedikit akan menghasilkan jumlah lulusan peserta Diklat yang jauh lebih banyak. Adanya 
kerjasama dengan organisasi mitra tidak hanya berfungsi untuk membantu menjaga kualitas diklat di lokasi grup online, tetapi juga mendapatkan para sukarelawan pegiat online di daerah yang bertugas sebagaipetugas lapangan.

Lebih lanjut Hasil wawancara dengan salah satu petugas lapangan pun juga mengatakan bahwa tingkat kehadiran peserta rata-rata mencapai $90 \%$, dan peserta sangat antusias.

5. Revisi ujicoba Lapangan Utama

Produk Model dan panduan mengalami revisi lagi setelah mendapatkan masukan di tahap sebelumnya. Model manajemen Diklat guru pendamping muda PAUD dapat diterapkan dan bisa direkomendasikan untuk di ujicobakan secara masif di uji coba operasional.

\section{PEMBAHASAN}

Peningkatan kompetensi guru PAUD merupakan hal yang sangat penting, karena guru PAUD lah pembentuk generasi yang paling awal setelah pendidikan di keluarga. Guru PAUD harus dibekali pengetahuan dan keterampilan yang memadai agar mampu mengajar dan mendidik anak usia dini dengan maksimal di lembaganya. Hal ini sesuai dengan hasil penelitian Manning (2017) yang menunjukkan bahwa kualifikasi dan kompetensi guru yang lebih tinggi terkait dengan peningkatan dalam mendukung perkembangan anak, termasuk mendukung pengalaman penalaran bahasa, pengawasan dan penjadwalan kegiatan, pengaturan ruangan, pemberian beragam pengalaman sosial untuk anak-anak, dan menciptakan lingkungan yang hangat dan ramah untuk interaksi.

Peningkatan kompetensi guru PAUD dapat dilakukan melalui berbagai macam kegiatan. Salah satu bentuk peningkatan kompetensi guru adalah kegiatan diklat. Penelitian inimengembangkan model manajemen diklat guru pendamping muda PAUD melalui media online. Pada awalnya dimulai dengan tahap penelitian dan pengumpulan

informasi

tentang

penyelenggaraan diklat sebelumnya dan

kelemahan diklat sebelumnya. Hasilnya Diklat guru pendamping muda PAUD yang sudah pernah dilaksanakan sudah mengacu pada pedoman yang telah dikeluarkan oleh kementerian pendidikan dan kebudayaan dan hasilnya para penyelenggara diklat sudah melaksanakan diklat sesuai pedoman yang ada sehingga kualitas lulusannya baik. Hal ini sesuai dengan penelitian oleh Riza (2014) menunjukkan bahwa Diklat berjenjang memiliki banyak dampak positif seperti peningkatan dalam kualitas dan jumlah hasil karya, efisiensi pembuatan media pembelajaran, serta kualitas pelayanan terhadap anak.

Walau demikian tetap masih ada permasalahan bagi penyelenggara terkait jumlah dana yang dianggarkan pemerintah, keterbatasan jumlah sumber daya manusia untuk menangani Diklat, dan kurangnya koordinasi antar panitia dalam rangkaian proses Diklat. Lebih lanjut hasil wawancara dengan salah satu pengurus organisasi guru PAUD, mengatakan bahwa penyelenggaraan diklat ditinjau dari sisi peserta diklat terdapat kelemahan dalam hal waktu dan tempat, karena peserta harus meninggalkan tugas selama seminggu di lokasi yang cukup jauh untuk dapat mengikuti Diklat guru pendamping muda ini, sementara sumber daya manusia di lembaga PAUD jumlahnya terbatas.

Solusi atas hal tersebut adalah dengan adanya diklat yang memanfaatkan teknologi informasi dan komunikasi/internet. Teknologi ini telah menjadi alat bagi khalayak dunia pendidikan untuk pengajaran dan pembelajaran. Diklat online memungkinkan proses transfer pengetahuan yang lebih fleksibel dari segi waktu, jarak, dan interaktif serta pengurangan biaya (Arzovski, 2007:1).

Peneliti kemudian menyusun perencanaan yang menjadi cikal bakal model manajemen Diklat guru pendamping muda 
PAUD melalui media online, sebagai solusi permasalahan yang di temukan. Model disusun sebagai acuan para penyelenggara Diklat, yang akan menyelenggarakan Diklat guru pendamping muda melalui media online. Model dilengkapi dengan adanya panduan bagi fasilitator, panduan bagi petugas lapangan dan panduan bagi peserta, yang menjelaskan secara teknis tugas masing-masing pihak dan bagaimana cara terlibat dalam diklat.

Produk pengembangan ini melalui beberapa tahap sampai akhirnya mendapatkan versi yang siap di ujicobakan. Model dan panduan-panduan tersebut melalui proses validasi oleh para ahli. Kemudian produk di revisi dan di uji oleh pihak-pihak yang terlibat dalam diklat, seperti penyelenggara, fasilitator, petugas lapangan dan peserta, umtuk mengetahui kelayakannya. Kemudian produk di revisi kembali sesuai dengan masukanmasukan yang ada, dan di ujicobakan ditahap ujicoba utama.

Hasil penelitian pengembanganpada tahap ujicoba utama menunjukkan bahwa, hasil yang didapatkan rata-rata hasil pretest peserta adalah 58, sedangkan rata-rata hasil posttest peserta adalah 90, sehingga ada kenaikan sebesar 32 poin. Hasil itu berarti bahwa model Diklat guru pendamping muda melalui media online efektif meningkatkan kompetensi peserta. Dilihat dari hasil kelulusannya pun dari 111 orang yang mengikuti diklat hanya ada 2 orang yang tidak lulus, atau 98,2\% kelulusannya.Hasil wawancara dengan salah satu petugas lapangan pun juga mengatakan bahwa tingkat kehadiran peserta rata-rata mencapai $90 \%$, dan peserta sangat antusias. Hal tersebut sesuai penelitian sebelumnya oleh beberapa orang dan hasilnya menunjukkan bahwa Diklat online lebih efisien dari sisi anggaran, efektif dan mendapat respon baik dari peserta (Kartini, 2018; Rahman, 2018; Utami, 2018).

Data Perbandingan alokasi dananya pun juga menunjukkan angka yang lebih rendah jika diselenggarakan secara online, dan bahkan dengan dana lebih rendah bisa meluluskan jumlah peserta yang tidak terbatas. Adanya kerjasama dengan organisasi mitra berfungsi untuk efisiensi dan pengendalian mutu diklat.

Kebijakan pendidikan dalam hal penyelenggaraan diklat guru pendamping muda melalui media online ini diambil PP PAUD dan Dikmas Jawa Tengah diarahkan bagi pemenuhan kebutuhan guru PAUD yang belum tersentuh diklat berjenjang. Hal tersebut sesuai dengan pendapat Tilaar dan Nugroho (dalam Madjid, 2018: 26) yang menyatakan bahwa titik tolak dari segala kebijakan pendidikan adalah untuk kepentingan peserta didik (peserta diklat).

\section{SIMPULAN DAN SARAN}

Berdasarkan temuan dan pembahasan hasil penelitian pengembangan seperti dipaparkan sebelumnya, dapat disimpulkan tiga hal sesuai dengan permasalahan penelitian yang telah dirumuskan yaitu bahwa (1) Diklat guru pendamping muda PAUD yang sudah pernah dilaksanakan di Jawa Tengah sudah mengacu pada pedoman yang telah dikeluarkan oleh kementerian pendidikan dan kebudayaan; (2) Kelemahan penyelenggaraan diklatdi Jawa Tengah, bagi penyelenggara terkait jumlah dana yang dianggarkan pemerintah, keterbatasan jumlah sumber daya manusia untuk menangani Diklat, dan kurangnya koordinasi antar panitia dalam rangkaian proses Diklat. Dilihat dari sisi peserta Diklat terdapat kelemahan dalam hal waktu dan tempat, karena peserta harus meninggalkan tugas; (3) Model Diklat guru pendamping muda melalui media onlinemeniliki produk utama berupa model, panduan bagi fasilitator, panduan bagi petugas lapangan dan panduan bagi peserta. Model efektif meningkatkan kompetensi peserta, serta efisien dari segi dana/anggaran. 


\section{DAFTAR PUSTAKA}

Arsovski, Zora., Stefanovic., Milano \& Arsovski. Slavco. 2007. Effectiveness of E-Learning. International Journal for Quality research. UDK 37.018.432:004.738.5 Professional Paper (1.04)

Borg, Walter., Gall, Meredith. 1983. Educational Research An Introduction. New York: Longman Inc. 4 Th Edition

Budiyanto, Arif., Pujiyono, Wahyu. 2014. Sistem Broadcast Proses Belajar Mengajar dengan Synchonous dan Asynchronous. Jurnal Sarjana Teknik Informatika. Vol 2 no. 1 Jogjakarta

Ditjen PGTK PAUD dan Dikmas. 2018. Pedoman Diklat Guru pendamping muda. Jakarta: Kemendikbud

Kartini, Tintin. 2018. Studi Evaluatif Kurikulum Diklat Berjenjang Tingkat Dasar Dalam Jaringan Terhadap Peningkatan KompetensiPendidik PAUD. Jurnal PLS. Vol. 2 No. 2

Kemendikbud. 2018. Laporan pemetaan mutu PAUD dan Dikmas. Jakarta

Kemendikbud. 2015. Renstra Kemendikbud 2015-2019. Jakarta

Madjid, Abd. 2018. Analisis Kebijakan Pendidikan. Yogyakarta: Samudra Biru

Manning, Matthew., Garvis Susanne. 2017. The Relationship Between Teacher
Qualification and The Quality of the Early Childhood Education and Care Environment. Campbell Collaboration

Kemdikbud. 2018. Laporan pemetaan mutu PAUD dan Dikmas. Jakarta

PP PAUD dan Dikmas Jawa Tengah. 2018. Laporan Diklat. Semarang

Pribadi, Benny A,. 2014. Desain dan Pengembangan Program Pelatihan Berbasis kompetensi: Implementasi Model ADDIE. Jakarta: Prenada Media Grup

Rachman, Taufik. 2018. Education and Leveled Training Management of Basic Levels on Network to Improve The Competence of PAUD Teachers. Journal Empowerment. Vol. 7 No. 2

Riza, Eva. 2014. Efektivitas Diklat Berjenjang Tingkat Dasar PTK PAUD. Jurnal Pendidikan Usia Dini. Vol 8. UNJ

Terry. G R. 1956. The Irwin Series in Industrial Engineering and Management: Principles of Management. Homewood Ill. University of Michigan

Utami, Dian BF. 2018. Efektivitas model etraining Diklat dasar pendidik PAUD PP PAUD dan Dikmas Jawa Tengah. Semarang

www.bps.go.id . 2018. APK PAUD. Jakarta 